\title{
Bioprodutos a partir de Resíduos da Produção de Cápsulas Derivadas de Gelatina Bovina
}

A inovação tecnológica é a introdução de um novo produto ou processo no mercado de um novo produto ou processo, ou de uma versão melhorada de um produto ou processo existente e, de forma geral, compreende: (1) as atividades internas e externas de Pesquisa, Desenvolvimento e Inovação (PD\&I); (2) a aquisição externa de PD\&I e outros conhecimentos externos; (3) o projeto industrial e (4) outras preparações técnicas para a produção e a distribuição. Inovação tecnológica, portanto, pode ser vista como sinônimo de geração de riqueza para uma região, especialmente, para seus Arranjos Produtivos Locais (APL) de algum segmento produtivo, e para a sociedade e suas entidades privadas e públicas. As atividades de PD\&I englobam a pesquisa em ciências básica e aplicada, visando obter aplicações inovadoras, a instalação de novos processos, sistemas e serviços, e ainda a melhora substancial do que já existe ou está instalado.

A obtenção de um material polimérico biodegradável, sem conservantes e oxidantes, podendo se decompor facilmente na natureza pela ação de micro-organismos, sem agredir o meio ambiente, é fundamental para melhor destinação dos resíduos da produção de cápsulas derivadas de gelatina. Com esse material, serão feitos estudos, com intuito de obter um biofilme que será desenvolvido para concorrer com os filmes sintéticos e outros produtos plásticos, derivados do petróleo que, pela sua não degradação, comprometem a natureza e avolumam-se em terrenos, lixões e mananciais. Para desenvolvimento deste trabalho, utilizando os descartes de produção, gerados na confecção de cápsulas de produto medicamentoso, à base de colágeno, proveniente do couro bovino, é necessária a realização de pesquisa com intuito de desenvolver formulações de biofilmes que tenham como matéria-prima principal estes resíduos. O material residual das cápsulas receberá aditivos, como: plastificantes, lubrificantes e cargas de reforço, que tornarão este material um plástico biodegradável com características químicas, físicas e físico-químicas, semelhantes às dos plásticos sintéticos, derivados do petróleo e que sejam adequadas para produção de um filme. Com os resultados obtidos, concluem-se quais seriam potenciais produtos confeccionados a partir do biofilme feito, como exemplo, as sacolas plásticas, usadas em grande volume no comércio varejista.

A inovação objetivada é a descoberta de um biofilme que, por meio de processos tecnologicamente desenvolvidos e criados a partir de análises laboratoriais químicas, físicas e físico-químicas, permitirá à empresa gestora do projeto desenvolver processos produtivos otimizados, com vistas a ganhos de produtividade e competitividade. Define-se como mercado potencial todo o segmento produtor/distribuidor de filmes plásticos com fins de transformação em subprodutos derivados do biofilme.

$\mathrm{O}$ projeto proposto tem o caráter de apresentar um produto inovador no mercado nacional de filmes plásticos, criado a partir da transformação de resíduos derivados da cápsula para medicamento farmacêutico. Esta cápsula é produzida pela empresa parceira neste projeto, Gênix Indústria Farmacêutica Ltda., estabelecida em Anápolis, especificamente, além de outra indústria concorrente instalada em São Paulo. Ambas convivem com o problema de armazenagem de grande estoque de resíduos e rejeitos deste 
produto, pela sua característica de agressividade ao meio ambiente. Trata-se de um produto derivado de gelatina bovina, portanto, orgânico. Contudo, no processo produtivo, são agregados corantes de tonalidades diversas, o que impede seu descarte no meio ambiente. Pretende-se desenvolver estudos e análises tecnológicas e laboratoriais neste processo com vistas à transformação dos resíduos de cápsulas em polímero biodegradável para uso e consumo no mercado, em substituição aos produtos similares, derivados petróleo, que são poluentes do meio ambiente. Pesquisas técnico-científicas realizadas em fontes confiáveis atestam a inexistência do produto ou de existência de patentes nos principais órgãos de registros no país e no exterior. Além de seu caráter inovador, o projeto criará oportunidades de geração de emprego e renda, , bem como permitir aumento continuado do faturamento e lucro da empresa Gênix. $\mathrm{O}$ estoque significativo desses insumos, armazenados, por não poderem ser descartados no meio ambiente, quer sejam despejados ou incinerados, transformar-seão em uma nova fonte de renda para a empresa.

\section{DESAFIOS TECNOLÓGICOS}

O biofilme ou filme biodegradável concorre com o filme sintético e outros produtos plásticos, derivados do petróleo que, pela sua não degradação, comprometem a natureza e avolumam-se em terrenos, lixões e mananciais. Os micro-organismos presentes na água e/ou solos não reconhecem as moléculas de cadeias carbônicas, presentes nos produtos não biodegradáveis. Trata-se, portanto, de um produto orgânico tecnologicamente transformado para ser aproveitado. Para desenvolvimento deste trabalho, utilizando os descarte de produção, gerados na confecção de cápsulas de produtos medicamentosos à base de colágeno, provenientes de couro bovino, é necessária a realização de pesquisa para desenvolver formulações de biofilmes que tenham como matériaprima principal estes resíduos. O material residual das cápsulas receberá aditivos como: plastificantes, lubrificantes e cargas de reforço, que tornará este material um plástico biodegradável com características químicas, físicas e físico-químicas semelhantes as dos plásticos sintéticos derivados do petróleo e que sejam adequadas para produção de um filme.
Atualmente, esses resíduos e rejeitos de cápsulas não podem ser descartados na natureza, seja aterrando, incinerando ou depositando em mananciais. Por isso, a empresa armazena todo resíduo gerado sem nenhum ganho, apenas prejuízo econômico e ambiental. Seu principal concorrente será a indústria de plásticos, que há mais de 40 anos, fabrica produtos diversos, derivados de resinas sintéticas, originadas do petróleo, com grande poder de durabilidade quando descartados na natureza. Já há décadas, o uso de polímeros derivados do petróleo produto fóssil e altamente agressivo ao meio ambiente, assim como seus subprodutos e derivados, são consumidos de forma acentuada na sociedade. Notadamente, os derivados de policloreto de vinila (PVC), polietileno (PE), poliestireno (PS) e polipropileno (PP), entre outros, são matéria prima largamente usada na fabricação de filmes e embalagens plásticas, em geral.

A cristalografia de Raios X, uma metodologia de determinação estrutural, baseada no fenômeno de difração, possibilita o conhecimento da distribuição espacial dos átomos para uma molécula, desde que se apresente no estado cristalino. Neste aspecto, o seu uso se permite o entendimento do experimento de fenda única para a localização de máximos e mínimos, a interpretação do padrão de difração gerado por sólidos cristalinos e a descoberta de estruturas químicas. Durante o processo de interação, a matéria pode espalhar a radiação incidente. Um tipo de espalhamento que é usado para análise cristalográfica são os gerados por raios X, quando interagem com uma distribuição particular da densidade eletrônica de um dado cristal, cuja dimensão de onda e as distâncias interatômicas são semelhantes. A difração para um cristal é um processo complexo e a interação dos Raios X com a matéria cristalina é normalmente descrita pelo entendimento de dois efeitos: espalhamento e interferência. Os resultados da interferência da radiação espalhada são utilizados para se obter o mapa de densidade eletrônica da estrutura que difratou os Raios X. Num passo inicial, determina-se a localização de regiões de interferência construtiva. De posse desse atributo, faz-se análise do espalhamento em diferentes casos, nos quais, para um arranjo molecular dito amorfo, o resultado da interferência apresentará irregularidade, não sendo totalmente destrutiva nem 
totalmente construtiva, ao passo que, para a disposição cristalina, obtém-se um padrão de difração regular, em decorrência da interferência das ondas espalhadas que se reforçaram em localizações específicas e em direções apropriadas, obedecendo a uma regularidade.

Os dados do experimento de difração de Raios $\mathrm{X}$ consistem apenas nas intensidades e nas posições das reflexões difratados, a partir das quais se pode obter a amplitude dos fatores de estrutura e, a partir destes, a estrutura molecular e cristalina. No entanto, toda informação relacionada à fase dos fatores de estrutura é perdida durante o experimento, o que impossibilita a determinação analítica da estrutura, a partir das intensidades medidas. Dessa forma, a metodologia cristalográfica consiste em desenvolver fatores de estrutura para cada reflexão coletada e, assim, construir a densidade eletrônica para o cristal. Isso é possível, devido ao fato de $\rho(\mathrm{x}, \mathrm{y}, \mathrm{z})$ ser a transformada de Fourier do fator de estrutura, relação dada por:

$$
\rho(x, y, z)=\frac{1}{V} \sum \sum \sum F_{h k l} e^{-2 \pi i(h x+k y+l z)}
$$

Uma vez que essas informações sejam obtidas e as posições dos átomos precisamente conhecidas, determinam-se as distâncias interatômicas os ângulos de ligação, as conformações, a planaridade da molécula, dentre outras características. No presente contexto, propõe-se obter a estrutura da chalcona usando o método cristalográfico, determinando a orientação e a distribuição da geometria deste composto.

\section{IMPACTOS}

É interesse da empresa, com resultados esperados, alimentar a elaboração de projeto de viabilidade econômico-financeiro para instalação de uma unidade industrial para produção deste produto inovador, inexistente em qualquer parte do mundo. Portanto, este novo produto, mostra-se viável economicamente devido:
1. Ao baixo custo do principal insumo (resíduos e fragmentos de cápsulas gelatinosas);

2. À diminuição dos custos para armazenagem desses resíduos, gerados na produção, e também uma nova alternativa para as embalagens ecologicamente corretas.

3. À empresa parceira e mentora do projeto que poderá descartar corretamente seu estoque de rejeito, atualmente estimado em mais de 150 toneladas;

4. À possibilidade de incrementar sua lucratividade, a partir da venda dos resíduos de cápsulas;

5. À possibilidade de fomentar a geração de emprego e renda com a criação de uma nova unidade industrial, quer seja diretamente, quer seja via capital terceirizado e

6. À ampliação de oportunidades de empregos qualificados.

O projeto proporcionará a redução do descarte direto de resíduos orgânicos no meio ambiente, evitando o impacto destes materiais no solo, ar e água diminuindo a interferência a fauna e flora e consequentemente melhorando a qualidade de vida das pessoas, tanto em Anápolis, como em outras cidades de Goiás. Outro ponto importante a ser mencionado é quanto ao desenvolvimento de um polímero biodegradável que poderá substituir os polímeros tradicionais derivados de petróleo.

\section{Hamilton Napolitano*, Fernando Afonso, Valter Carvalho \& Ivan Teixeira}

Pesquisadores que atuam em projeto de desenvolvimento de bioprodutos

*E-mail: hnapolitano@pq.cnpq.br 